\title{
Pengembangan Sistem Modul Komisi Dinamis pada Modul Penjualan ERP - Odoo12
}

\author{
Danang Wahyu Utomo ${ }^{1 *}$, Defri Kurniawan², Egia Rosi Subhiyakto ${ }^{3}$ \\ 1,2,3Program Studi Teknik Informatika, Universitas Dian Nuswantoro \\ 1,2,3 Jln. Imam Bonjol 207, Semarang, 50131, Indonesia \\ E-mail: danang.wu@dsn.dinus.ac.id ${ }^{1}$, defri.kurniawan@dsn.dinus.ac.id ${ }^{2}$, egia@ dsn.dinus.ac.id ${ }^{3}$
}

\section{Info Naskah:}

Naskah masuk: 30 Mei 2021

Direvisi: 16 Agustus 2021

Diterima: 18 Agustus 2021

\begin{abstract}
Abstrak
Peningkatan sistem penjualan tidak hanya fokus pada hasil dari keuntungan transaksi penjualan tetapi juga melihat parameter lain dalam peningkatan sistem tersebut. Salah satu aspek yang digunakan adalah komisi. Pemberian komisi kepada sales dapat menigkatkan kinerja sales dan berdampak pada peningkatan target penjualan. Permasalahan yang dihadapi suatu perusahaan adalah adanya ketidaksesuaian pemberian komisi. Hal ini disebabkan oleh beberapa factor seperti sistem komisi tidak terintegrasi dan sistem perusahaan, formula yang tidak tepat, atau banyaknya sistem yang digunakan oleh perusahaan sehingga para staf kesulitan untuk mengintegrasikan sistem tersebut. Sebagai contoh, perusahaan menggunakan Odoo ERP sebagai penunjang proses transaksi penjualan dan menggunakan sistem informasi secara terpisah. Para sales harus mengintegrasikan data penjualan ke sistem tersebut. Hal ini menyebabkan lambatnya waktu pemberian komisi. Berdasarkan permasalahan diatas, kami mengusulkan pengembangan prototype sistem komisi yang terintegrasi dengan Odoo12. Para sales tidak perlu mengintegrasikan secara manual data perusahaan karena sistem secara otomatis akan mengintegrasikan. Penelitian ini menggunakan prototyping model sebagai metode pengembangan sistem. Hasil penelitian adalah sistem komisi layak diimplementasikan pada Odoo12 ERP guna menentukan pemberian komisi kepada sales, $70 \%$ responden setuju bahwa sistem mampu digunakan untuk pengaturan modul komisi dalam Odoo.
\end{abstract}

\section{Keywords:}

sistem komisi penjualan; enterprise resource planning; odoo12;

prototype.

\begin{abstract}
The improvement of the sales system not only focuses on the advantage result of the sales transaction but also can use another parameter to improve it. One of a parameter used is commission. Giving commissions to the salesperson can improve their work performance and have an impact on increasing sales targets. Based on the study literature, the problem faced by the company is the discrepancy of commission. It can be affected by several factors such as the commission system are not integrated with the main system, improper formula, or there are many systems used in the company so it the staff are difficult to integrate the system. For example, the company using Odoo ERP to support sales transaction and use commission information system separately. The salesperson must integrate sales data into both of the systems. It can affect the time delay of decision commission. Based on the problem above, we propose a prototype commission system that integrates with Odoo12. The salesperson does not need to integrate data manually into the system because it automatically integrates into the system. This study uses a prototyping model as a software development method. The results show that the commission system can implement on the Odoo12 ERP to decide commission to the salesperson. $70 \%$ of respondent agree that system has able to use in order to setting up commission module on Odoo.
\end{abstract}




\section{Pendahuluan}

Persaingan dalam dunia bisnis menjadi perhatian utama bagi pelaku bisnis atau perusahaan. Beberapa perusahaan mengusulkan strategi dan inovasi guna mendapatkan keuntungan, pelanggan tetap dan kuantitas penjualan yang lebih tinggi dibandingkan pesaingnya. Salah satu strategi yang saat ini diusulkan adalah penerapan teknologi sistem informasi. Berapa perusahaan menerapkan sistem informasi untuk menunjang bisnis proses [1], pengembangan sistem informasi untuk menunjang pengetahuan proses bisnis digital marketing [2] dan sistem informasi bagi usaha kecil mikro menengah guna meningkatkan pelayanan bisnis kepada konsumen [3].

Salah satu sistem yang banyak diusulkan dalam menunjang proses bisnis adalah Odoo. Odoo merupakan open-source ERP (Enterprise Resource Planning) yang memiliki fitur manajamen bisnis proyek, hubungan pelanggan, sumber daya manusia, penjualan, akuntansi dan inventaris [4]. Sedangkan ERP adalah sebuah aplikasi manajemen bisnis yang mampu menunjang pengelolaan bisnis secara integrasi. Menurut [5] ERP merupakan sekumpulan program terintegrasi yang mampu mengelola proses bisnis perusahaan untuk seluruh organisasi. Bagi perusahaan dengan bisnis proses yang kompleks, ERP sangat membantu untuk menunjang segala proses bisnis di masing - masing organisasi atau divisi.

Saat ini, ERP banyak digunakan oleh perusahaan perusahaan guna mendukung kebutuhan perusahaan. Bagi perusahaan yang fokus pada modul penjualan, ERP mampu digunakan untuk mendukung kecepatan dan ketepatan penjualan produk ke pelanggan (customer). Efisiensi waktu dan ketepatan menjadi hal utama untuk meningkatkan nilai dan kualitas sebuah perusahaan. Factor lain yang digunakan untuk meningkatkan penjualan suatu produk adalah komisi.

Sistem komisi adalah pemberian suatu imbalan yang diberikan karena jasa dalam jual beli. Beberapa penelitian menunjukkan bahwa beberapa perusahaan telah menggunakan sistem komisi dalam proses bisnis. Pemberian komisi terhadap agen pemasaran mampu meningkatkan rasio penjualan [6]; Sistem komisi juga mampu digunakan untuk meningkatkan kualitas kerja dari agen sales dalam performa peningkatan rasio penjualan tiap agen sales [7]; sistem informasi untuk membantu penghitungan komisi agen asuransi [8]; sistem pemberian komisi disusulkan kepada agen karena pemberian komisi sering terjadi kesalahan [9]; dan sistem informasi yang diusulkan untuk memantau laporan komisi dari agen sales [10].

Berdasarkan studi literatur diatas, dapat disimpulkan bahwa pengusulan sistem informasi komisi baru dapat menjadi penghambat dalam proses bisnis. Sistem informasi belum tersinkron dengan sistem perusahaan. Bagi perusahaan yang telah menggunakan Odoo, perusahaan harus melakukan dua kali proses eksekusi yaitu di Odoo ERP dan sistem informasi yang diusulkan. Permasalahan yang terjadi adalah menyebabkan bertambahnya waktu untuk eksekusi pemberian komsisi pada agen (salesperson). Satu waktu digunakan untuk menjalankan proses di sistem informasi yang baru, satu waktu lainnya digunakan untuk menjalankan Odoo ERP. Permasalahan lainnya adalah memungkinkan terjadinya kesalahan data dan informasi karena tidak adanya sinkronisasi data antara Odoo dan sistem informasi yang diusulkan. Maka, kesalahan dalam penentuan besaran komisi yang diberikan kepada agen dapat terjadi. Sebagai contoh, besaran komisi yang diberikan kepada agen tidak sesuai dengan besaran target yang dilaporkan atau besaran komisi melebihi dari target.

Pada penelitian ini diusulkan pengembangan modul komisi penjualan pada Odoo 12 yang sebelumnya tidak ada modul untuk menunjang kebutuhan perusahaan terkait pemberian komisi penjualan. Modul komisi yang dikembangkan dapat secara otomatis terintegrasi dengan Odoo. Tujuannya, untuk mengurangi lamanya waktu proses eksekusi dan mengurangi kesalahan dalam penentuan besaran komisi penjualan kepada agen. Pengembangan sistem komisi pada Odoo12 menggunakan web framework dengan metode evaluasi pengujian adalah blackbox dan user acceptance testing (UAT). Metode blackbox digunakan untuk menguji apakah hasil sistem sesuai dengan perancangan. Metode UAT digunakan untuk menguji sistem dengan melibatkan responden seperti manager, salesperson dan pegawai lain yang terlibat dalam penggunaan sistem. Pengujian UAT menggunakan metric pengujian yang disesuaikan dengan topik penelitian yaitu sistem komisi.

\section{Metode}

\subsection{Enterprise Resource Planning (ERP)}

Enterprise Resource Planning (ERP) merupakan sistem yang mampu mengintegrasikan bisnis proses dan informasi dalam lintas perusahaan dan mampu menyediakan informasi real-time sehingga dapat digunakan sebagai pendukung keputusan perusahaan [11] [12]. Saat ini ERP tidak digunakan oleh perusahaan besar, namun juga digunakan oleh perusahaan kecil dan menengah seperti UMKM [13]. Pada penelitian [14] menunjukkan bahwa Odoo merupakan perangkat lunak terbaik dalam menyediakan sistem ERP. Peneliti menyatakan bahwa Odoo handal, mudah digunakan dan mampu digunakan disemua level (small, medium, big) enterprise. Pada perusahaan yang bergerak dibidang penjualan, Odoo mampu digunakan untuk menunjang proses bisnis penjualan antara penjualan dan konsumen seperti data penjualan, detail produk, pembuatan nota struk atau invoice bagi konsumen, tabulasi penjualan dalam jangka waktu harian, mingguan atau bulanan.

Odoo ERP merupakan sebuah perangkat lunak bisnis open source dengan cakupan customer relationship management (CRM), manajemen proyek, penjualan, pembelian, dan sumber daya manusia [4]. Adanya cakupan dan fokus bisnis tersebut, Odoo dikembangkan dalam berbagai modul. Salah satu modul yang banyak digunakan oleh perusahaan adalah modul penjualan. Modul penjualan pada Odoo memiliki fitur-fitur seperti permintaan penjualan (order sales), kontrak (contract), nota penjualan (invoice), portal konsumen atau pelangan (customer portal). 


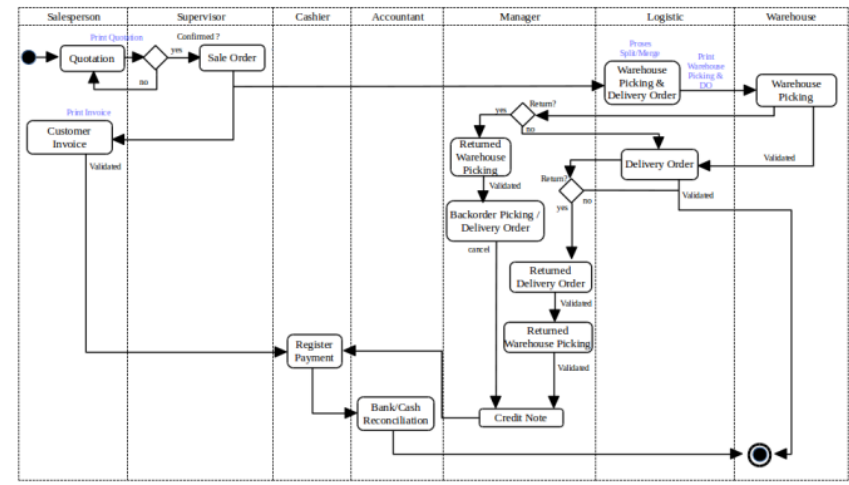

Gambar 1. Diagram Aktivitas Modul Penjualan

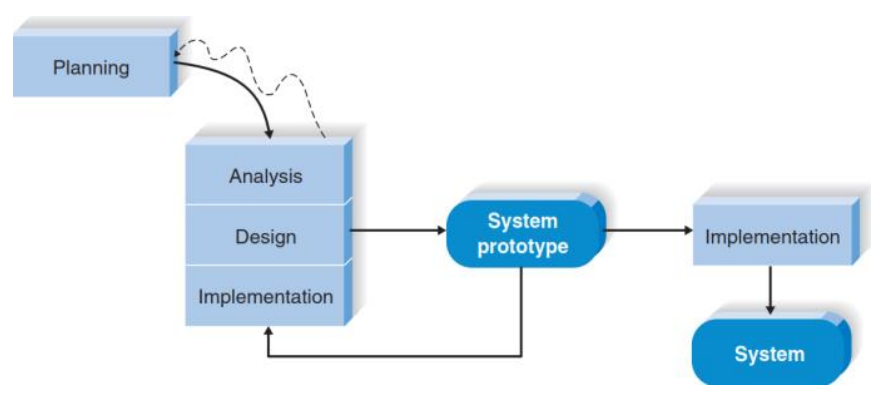

Gambar 2. Prototyping [15]

Fungsi utama modul penjualan ditujukan untuk fokus utama proses bisnis pada transaksi penjualan seperti barang masuk, transaksi keuangan, laporan hasil penjualan dan laporan kesesuaian target penjualan dan transaksi keuangan, dan komisi penjualan. Secara umum, proses penjualan adalah konsumen melakukan pemesanan. Pemesanan tersebut akan di konfirmasi menjadi sebuah sale order kemudian dianalisis oleh perusahaan kemudian proses akhir adalah pembuatan nota invoice pemesanan. Pada Gambar 1, menunjukkan proses pemesanan dimulai dari pemesanan dari konsumen yang terlebih dahulu di konfirmasi oleh supervisor, kemudian proses akan dilanjutkan ke bagian logistic dan terakhir adalah pengiriman barang dan pembuatan invoice pelanggan.

\subsection{Metode Pengembangan Sistem}

Pengusulan metode adalah metode pengembangan sistem dalam pengembangan perangkat lunak. Metode pengembangan sistem yang diusulkan adalah prototyping model [15]. Tahap pengembangan meliputi:

a) Perencanaan, tahapan meliputi pengumpulan kebutuhan yang dibutuhkan oleh sistem yaitu kebutuhan fungsional dan kebutuhan non fungsional sistem.

b) Analisis, penentuan sistem komisi ditentukan berdasarkan domain masalah atau topik penelitian data yang dikumpulkan dan elisitasi kebutuhan yang disepakati pada tahap perencanaan.

c) Desain, perancangan diagram sebagai bahan pengembangan sistem prototype. Pemodelan diagram menggunakan unified modeling language (UML) dengan diagram adalah use case diagram dan activity diagram.

d) Membangun prototype, pengembangan sistem versi beta berdasarkan analisis dan desain. Pengembangan sistem web framework menggunakan Bahasa pemrograman Python.

e) Hasil sistem, hasil akhir dari sistem yang telah dilakukan pengujian sebelumnya yaitu implementasi modul komisi pada Odoo12.

Tabel 1. List Pernyataan / Pertanyaan

\begin{tabular}{lll}
\hline No & $\begin{array}{c}\text { Pernyataan / } \\
\text { Pertanyaan }\end{array}$ & \multicolumn{3}{c}{ Keterangan } \\
\hline 1 & Jenis perusahaan & $\begin{array}{l}\text { Pernyataan digunakan untuk } \\
\text { menentukan topik dan spesifikasi } \\
\text { kebutuhan sistem yang saat ini } \\
\text { digunakan. }\end{array}$
\end{tabular}

2 Proses bisnis

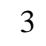

\section{Perangkat lunak yang digunakan}

Permasalahan yang dihadapi

Hasil yang diharapkan solusi sudah diterapkan ke masalah? saat ini?
Pernyataan digunakan untuk proses awal elisitasi yaitu penentuan domain dan alur masalah dalam penggunaan sistem.

Pernyataan digunakan sebagai bahan elisitasi kebutuhan perangkat lunak yang akan dikembangkan nantinya atau modul yang harus diusulkan

Pernyataan digunakan untuk menentukan elisitasi kebutuhan fungsional dan kebutuhan non fungsional dari data yang dikumpulkan.

Apakah sudah ada Pertanyaan digunakan untuk solusinya? kebutuhan negosiasi terhadap analisis atau elisitasi yang telah diusulkan dan disepakati oleh perusahaan.

Jika ada, Apakah Pertanyaan digunakan untuk penentuan terhadap kemungkinan kemungkinan yang muncul permasalahan lain seperti jaringan, responsive, waktu eksekusi dan bug dari program.

Jika belum, Pertanyaan digunakan untuk Apakah sudah melengkapi proses analisis domain menemukan solusi dan elisitasi dan menentukan secara

spesifik modul yang harus dikembangkan dalam sistem.

Pernyataan digunakan untuk menambahkan kebutuhan fungsional menurut versi stakeholder dan jenis perangkat lunak yang akan dikembangkan.

\subsection{Planning}

Planning adalah tahap perencanaan yang digunakan untuk dasar penentuan kebutuhan sistem. Tahap perencanaan terdiri dari penentuan domain, topik atau alur permasalahan dalam sistem dan pengumpulan data untuk mendukung pengembangan modul yang diusulkan. Tahap penentuan domain dan permasahan mencakup topik - topik yang akan dibahas, permasalahan yang saat ini dihadapi 
oleh PCI termasuk masalah dalam penerapan pengaturan komisi penjualan terhadap salesperson dan penentuan solusi yang diharapkan. Penentuan domain dan permasalahan ditentukan berdasarkan pernyataan dan pertanyaan seperti pada Tabel 1.

Tahap selanjutnya adalah pengolahan data yang ditujukan sebagai bahan dalam proses elisitasi kebutuhan fungsional dan kebutuhan non fungsional. Data Penelitian menggunakan data sampel nota penjualan atau invoice struk di tahun 2020. Pengolahan data dilakukan dengan tools PgAdmin, data yang diproses seperti pada Tabel 2.

\begin{tabular}{|c|c|}
\hline No & $\begin{array}{r}\text { Tabel 2. Data } \\
\text { Data }\end{array}$ \\
\hline 1 & Invoice number \\
\hline 2 & Nama (barang yang dipesan) \\
\hline 3 & Salesperson \\
\hline 4 & $\begin{array}{l}\text { Comission rule (aturan } \\
\text { komisi) }\end{array}$ \\
\hline 5 & Harga \\
\hline 6 & Kuantitas \\
\hline 7 & Komisi \\
\hline 8 & Data Warehouse \\
\hline
\end{tabular}

Pada Tabel 2, data yang diolah dapat digunakan sebagai bahan untuk penentuan nilai komisi (commission rule) sebagai berikut:

a) Nilai asli (original value) dari barang yang dipesan dikalikan dengan jumlah barang (quantity).

b) Nilai dari harga pada subtotal dikurangi dengan nilai a)

c) Kalikan nilai yang diperoleh pada b) dengan prosentase komisi yang berhubungann dengan salesperson.

\subsection{Analysis}

Analysis adalah tahap menganalisis penentuan domain dan hasil pengolahan data untuk digunakan dalam perancangan dan implementasi sistem. Pada Tabel 1, list pertanyaan yang diajukan kepada narasumber, menunjukkan tahap yang harus dilakukan dalam penelitian. Pada pernyataan 3, penentuan kebutuhan fungsional diawali dari analisis kebutuhan sistem yaitu kebutuhan perangkat lunak. Tujuannya untuk menemukan spesifikasi sistem yang telah digunakan oleh objek penelitian saat ini. Pada pernyataan 4, domain permasalahan ditentukan dengan elisitasi kebutuhan fungsional dan kebutuhan non fungsional. Kebutuhan fungsional adalah kebutuhan yang digunakan dalam menunjang pengembangan perangkat lunak. pada Tabel 2, sudah ditentukan bahwa pengembangan modul komisi membutuhkan kebutuhan fungsional: invoice number, nama barang, sales person, aturan komisi, harga, kuantitas, komisi, dan data warehouse.

\subsection{Perancangan Sistem}

Tahapan perancangan sistem direalisasikan dengan pemodelan diagram UML. Berdasarkan resume analisis, sistem komisi diberikan kepada pengguna yang terkait dengan penjualan (salesperson). Komisi dapat ditentukan berdasarkan nota invoice penjualan. Dalam hal ini actor yang berperan dalam sistem adalah manager dan salesperson. Manager berperan sebagai validasi commision rule dan laporan yang diajukan oleh salesperson. Salesperson berperan sebagai actor yang mengajukan invoice dan laporan berupa pemesanan (order) dari konsumen.
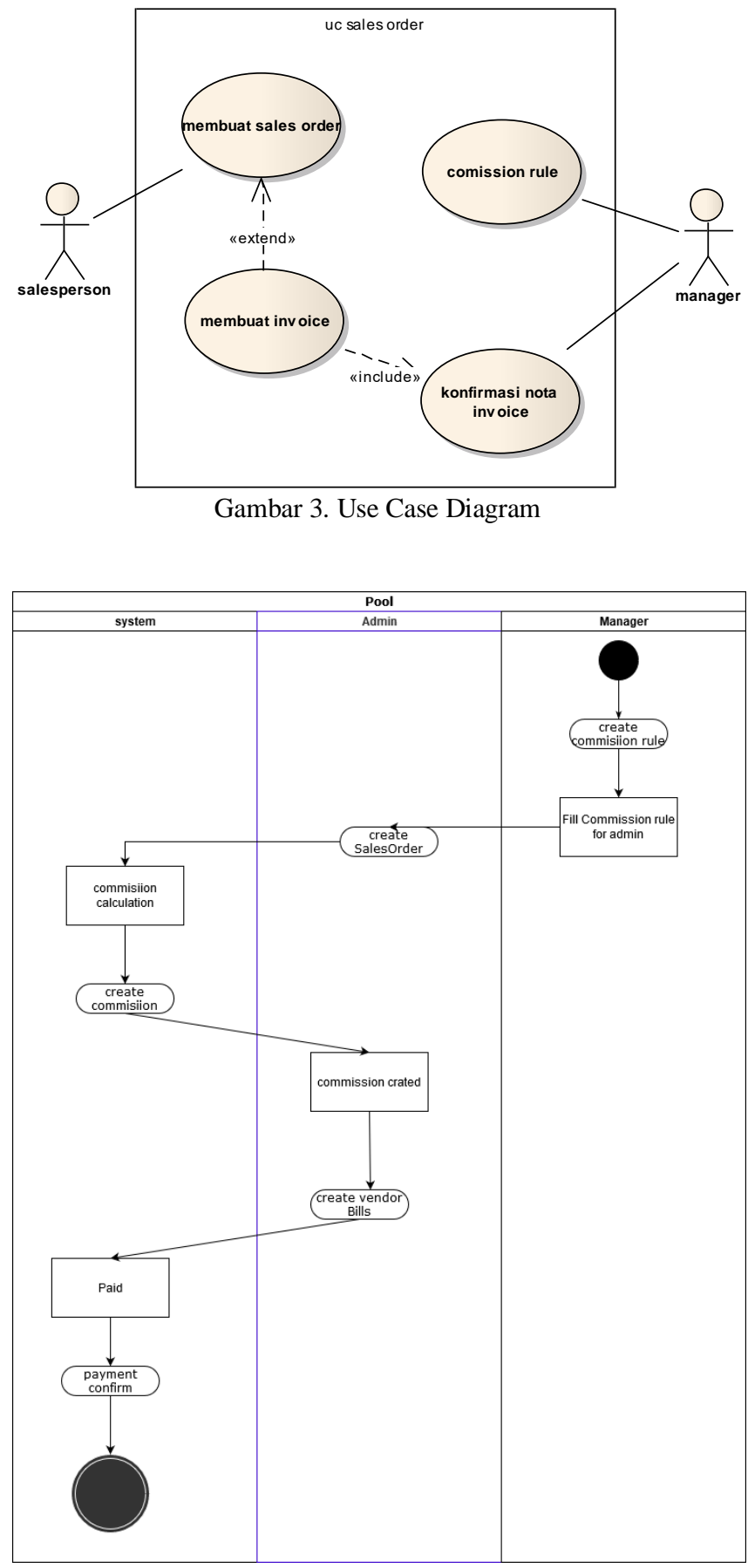

Gambar 4. Diagram Aktivitas

Gambar 3 menunjukkan perilaku dari actor dalam sistem komisi. Sesuai dengan resume analisis, invoice yang dibuat oleh salesperson akan dikonfirmasi terlebih dahulu oleh manager kemudian ditentukan comission rule.

Proses detail dapat ditampilkan pada diagram aktivitas. Diagram aktivitas menggambarkan proses 


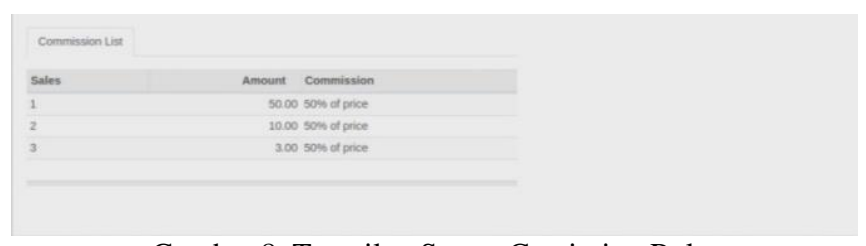

Gambar 8. Tampilan State - Comission Rule

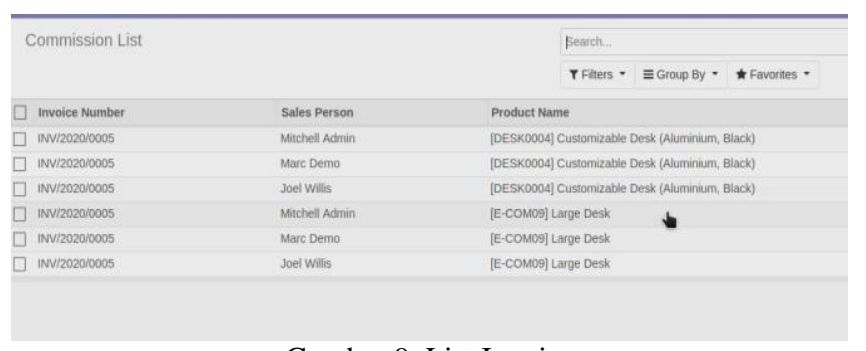

Gambar 9. List Invoice

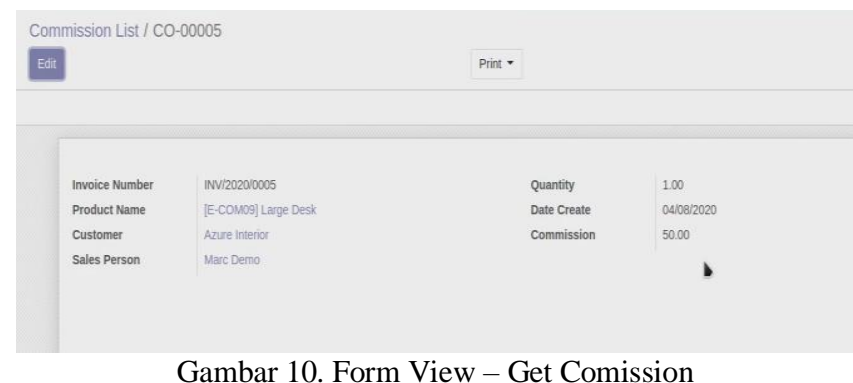

Berdasarkan Gambar 7 dan 8, besaran komisi akan diinputkan oleh manager. Dalam desain sistem, manager memiliki hak untuk mengatur ketentuan besaran komisi yang akan diberikan oleh salesperson. Pada form field commission rule, manager memiliki hak untuk menentukan besaran commision rule. Jika besaran komisi sudah dimasukkan oleh manager. Maka, pada Gambar 8, rule komisi akan ditampilkan kepada salesperson. Besaran target dan prosentase yang ditampilkan menjadi panduan utama bagi salesperson untuk mendapatkan komisi. Sebagai contoh; jika sales mampu memenuhi target 50 penjualan.

Maka, besaran komisi yang diperoleh adalah $50 *$ harga asli * besaran prosentase komisi: asumsi, harga asli adalah $200.000,-$. Besaran komisi adalah $50 *$ [200.000*50\%] $=$ $50 * 100.000=5.000 .000$.

Pada gambar 9 dan Gambar 10, menunjukkan tampilan bahwa setelah invoice dibuat dan dikonfirmasi maka secara otomatis sistem akan membuat komisi yang akan diperoleh oleh salesperson. Masing - masing salesperson akan mendapatkan besaran komisi yang berbeda berdasarkan target penjualan yang diperoleh. Hal ini dapat mengurangi ketidaksesuaian pemberian komisi kepada salesperson. Selain itu, salesperson dapat mengetahui secara detail masing-masing besaran komisi dari target penjualan yang dilaporkan.

Fitur selanjutnya adalah laporan. Pembuatan laporan melalui wizard memudahkan pemilik perusahaan untuk mengetahui transaksi yang dilakukan dan komisi yang diberikan. Sistem dapat melakukan export data ke dalam excel.

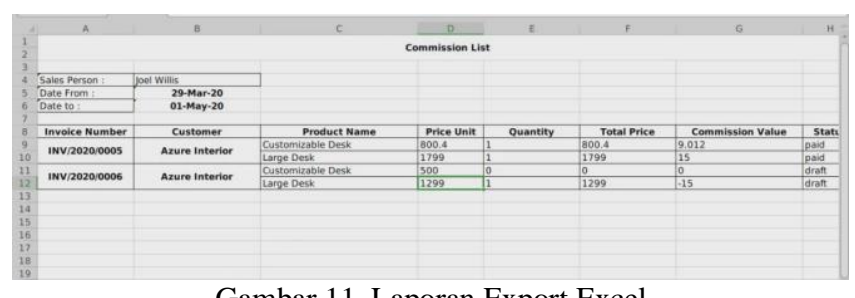

Gambar 11. Laporan Export Excel

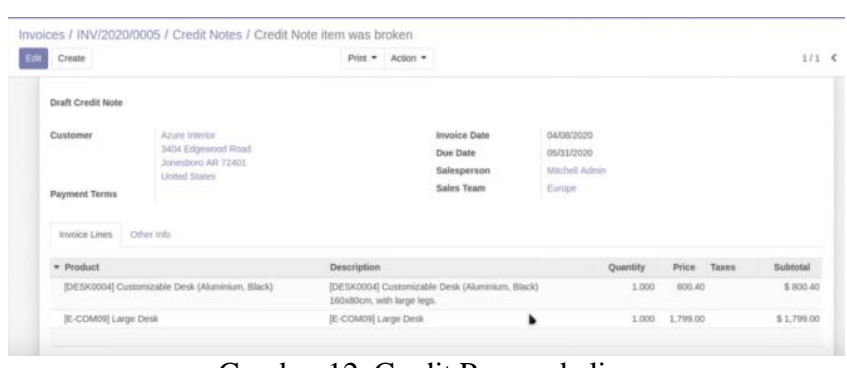

Gambar 12. Credit Pengembalian

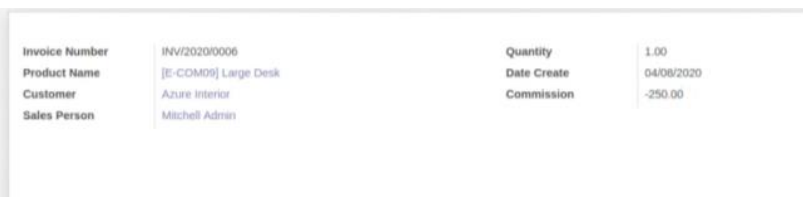

Gambar 13. Pengurangan Komisi

Pada Gambar 11 menunjukkan laporan dapat diekspor ke excel berdasarkan input tanggal. Hal ini memudahkan user untuk melakukan pengecekan secara berkala. Pada sistem komisi memiliki fitur pengurangan komisi, jadi pada suatu kondisi pihak konsumen melakukan pengembalian produk, maka sistem akan melakukan pengurangan komisi sesuai besaran pengembalian.

Pada Gambar 12 dan Gambar 13 adalah contoh jika konsumen melakukan pengembalian. Pada sistem sebelumnya pengurangan modul hanya menggunakan bukti laporan dari konsumen, yang akan disampaikan kepada manager. Kemudian, akan dicek validitasnya oleh manager. Namun, banyak bukti laporan yang hilang yang menyebabkan ketidaksesuaian laporan akhir dengan laporan pengembalian barang dari konsumen.

Pada sistem yang diusulkan, Odoo12 akan mengurangi komisi dari salesperson terkait. Besaran komisi akan dikurangi dengan nilai produk yang dikembalikan oleh konsumen. Salesperson akan menerima hasil terkait pengurangan komisi rule dan besaran kuantitasnya.

\subsection{Evaluasi dan Uji Sistem}

Tahapan evaluasi menentukan apakah sistem telah sesuai dengan dokumen yang dibuat (perencanaan). Pengujian sistem menggunakan pengujian black-box. Black box untuk menguji fungsi dan fitur apakah berjalan sesuai perencanaan dan melakukan pengecekan berdasarkan hasil yang ditampilkan oleh sistem.

Evaluasi sistem menggunakan user acceptance testing (UAT) sebagai evaluasi sistem yang melibatkan pengguna dan/atau stakeholder. UAT terdiri dari pertanyaan - 
pertanyaan seputar sistem ditujukan kepada pihak yang terlibat seperti salesperson, manager untuk mengevaluasi kesesuaian sistem yang dibangun. Pada pengujian UAT menggunakan materi uji seperti pengaturan komisi rule, usability, responsiveness, dan fungsionalitas.

\subsection{Pengujian Sistem}

Pengujian sistem komisi menggunakan black box dan UAT. Pengujian black-box melakukan pengujian berdasarkan kasus uji, hasilnya pada Tabel 3 .

Tabel 3. Uji - Black Box

\begin{tabular}{|c|c|c|c|c|}
\hline No & Kasus Uji & Skenario Uji & $\begin{array}{c}\text { Hasil yang } \\
\text { Diharapkan }\end{array}$ & $\begin{array}{c}\text { Hasil } \\
\text { Pengujian }\end{array}$ \\
\hline 1 & $\begin{array}{l}\text { Menu } \\
\text { Commission } \\
\text { rule }\end{array}$ & $\begin{array}{ll}\text { 1. } & \text { Pengujian } \\
& \text { Rule } \\
\text { 2. Penambahan } \\
\text { Komisi }\end{array}$ & $\begin{array}{l}\text { 1.Hanya } \\
\text { muncul di } \\
\text { halaman } \\
\text { Manager } \\
\text { 2.manager } \\
\text { dapat } \\
\text { menambahan } \\
\text { pengaturan } \\
\text { komisi }\end{array}$ & $\begin{array}{l}\text { 1. Berhasil } \\
\text { 2.Berhasil }\end{array}$ \\
\hline 2 & Fitur & $\begin{array}{l}\text { 1. Report Excel } \\
\text { 2. Wizard } \\
\text { 3.Tampilan } \\
\text { Report Excel }\end{array}$ & $\begin{array}{l}\text { 1.laporan } \\
\text { berbentuk } \\
\text { excel } \\
\text { 2.wizard } \\
\text { membentuk } \\
\text { ekspor excel } \\
\text { 3.tampilan } \\
\text { sesuai laporan } \\
\text { manual }\end{array}$ & $\begin{array}{l}\text { 1.Berhasil } \\
\text { 2.Berhasil } \\
\text { 3.Berhasil }\end{array}$ \\
\hline 3 & Button & $\begin{array}{l}\text { 1.Tombol } \\
\text { account invoice } \\
\text { ke comission list } \\
\text { 2.Tombol credit } \\
\text { note }\end{array}$ & $\begin{array}{l}\text { 1.menampilkan } \\
\text { invoice ke } \\
\text { comission list } \\
\text { 2.menampilkan } \\
\text { credit note dari } \\
\text { konsumen }\end{array}$ & $\begin{array}{l}\text { 1.Berhasil } \\
\text { 2.Berhasil }\end{array}$ \\
\hline
\end{tabular}

Pada Tabel 3, kasus uji hanya menampilkan unit - unit yang berkaitan dengan modul komisi seperti pembuatan commission rule, laporan komisi dan fitur pendukung untuk memasukkan data ke dalam commission list. setelah dilakukan pengujian, hasil menunjukkan bahwa modul sistem komisi berhasil diuji. Sebagai contoh, pada kolom hasil yang diharapkan merupakan target yang harus dipenuhi dalam tahap implementasi. Target telah direncanakan pada tahap perancangan. Jika hasil yang dari target tidak sesuai, maka harus dilakukan perbaikan kode program. Pada Gambar 8 menunjukkkan bahwa sistem menampilkan form input commission rule. Hal ini membuktikan bahwa pengujian black box dengan scenario uji penambahan komisi berhasil dilakukan. Pembuktian lainnya, pada Gambar. 12 sistem menampilkan tombol edit berhasil menampilkan credit note. Hal ini membuktikan bahwa scenario uji tombol credit note berhasil dilakukan.

Pengujian UAT dilakukan dengan memberikan kuesioner pertanyaan kepada salesperson dan manager selaku pengguna sistem. Penilaian pengujian menggunakan skala likert dengan skala uji 5.

\begin{tabular}{cl} 
& Tabel 4. Materi Kuesioner \\
\hline No & \multicolumn{1}{c}{ Materi } \\
\hline 1 & Pengaturan comission rule \\
2 & Pengaturan comission list \\
3 & Pengaturan wizard \\
4 & Credit Note \\
5 & User Interface \\
6 & Easy of use \& understand \\
7 & Responsive \\
8 & Fungsionalitas \\
9 & Performa \\
10 & Real-time \\
\hline
\end{tabular}

Pada Tabel 4, materi uji $1-4$ menguji sistem berdasarkan modul yang dipilih. Kasus uji yang diberikan adalah kemudahan pengguna menggunakan modul komisi, kesesuaian modul komisi dengan sistem yang dijalankan oleh perusahaan dan ketepatan hasil dari pengaturan modul tersebut.

Materi uji 5 dan 6 merupakan uji yang difokuskan pada faktor usability yang menilai ketertarikan pengguna terhadap tampilan sistem, fitur dalam sistem yang mudah digunakan seperti tombol, form pencarian dan ekspor dokumen. Materi uji tampilan pengguna digunakan untuk penyesuaian komponen kebutuhan non fungsional dalam sistem. Materi uji easy of use and understand digunakan untuk mengevaluasi apakah fungsi dari form pencarian, tombol seperti submit, cancel dan cari berfungsi dengan baik. Pengguna merasa mudah menggunakan fungsi dan tombol tersebut.

Materi uji 7 - 10 merupakan uji dengan fokus system metric yaitu menguji kemampuan sistem dalam memberikan umpan balik kepada pengguna seperti fungsi dapat dijalankan secara optimal, sistem menampilkan informasi dengan cepat, sistem menampilkan informasi secara up to date otomatis, performa tombol sesuai dengan halaman yang dituju.

Pada Tabel 5, Materi uji kuesioner diberikan kepada 30 responden acak dengan model survei. Pada materi uji setting sistem, hasil menunjukkan bahwa rata - rata responden menyatakan setuju 70\% (21 dari 30) bahwa sistem komisi memberikan kemudahan bagi pengguna, modul sesuai dengan rancangan yang ditetapkan dan hasil yang tepat. Dalam hal ini, dapat disimpulkan bahwa sistem yang dibangun telah sesuai dengan tahap perencanaan dan analisis dan desain.

Tabel 5. Hasil UAT

\begin{tabular}{cccccc}
\hline \multicolumn{7}{c}{ Materi Uji } & SA & A & N & D & SD \\
\hline Setting Sistem & & & & & \\
\hline 1 & 17 & 10 & 3 & 0 & 0 \\
2 & 15 & 6 & 5 & 4 & 0 \\
3 & 10 & 7 & 2 & 5 & 6 \\
4 & 5 & 14 & 1 & 10 & 0 \\
\hline Usability & & & & & \\
\hline 5 & 2 & 10 & 8 & 3 & 7 \\
6 & 2 & 12 & 2 & 6 & 8 \\
\hline Sistem Metric & & & & & \\
\hline 7 & 18 & 5 & 0 & 4 & 3 \\
8 & 0 & 17 & 5 & 4 & 4 \\
9 & 1 & 12 & 1 & 7 & 9 \\
10 & 5 & 5 & 8 & 10 & 2 \\
\hline
\end{tabular}


Note: Strongly Agree (SA), Agree (A), Neutral (N), Disagree (D), Strongly Disagree (SD).

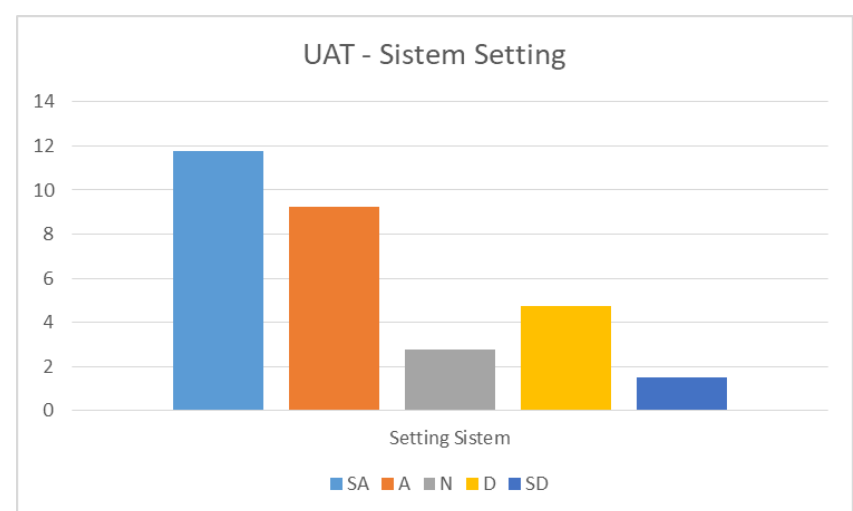

Gambar 14. Grafik UAT - Materi Uji Setting Sistem

Pada materi uji usability, hasil menunjukkan bahwa rata - rata responden menjawab 43\% (13 dari 30) setuju dan 40\% (12 dari 30) tidak setuju. Hal ini menyatakan bahwa sebagian besar responden setuju sistem komisi mampu menarik minat pengguna dalam menggunakan sistem dan fitur - fitur yang disediakan mudah digunakan.

Pada materi uji sistem metrik rata - rata responden menjawab 45\% (14 dari 30) setuju dan 36\% (11 dari 30) tidak setuju. Hal ini membuktikan bahwa sebagian besar responden menyatakan setuju sistem dapat memberikan umpan balik yang cepat, optimal dan sistem mampu memberikan informasi yang up to date.

Jika ditampilkan dalam bentuk grafik, pada Gambar 14 menunjukkan Komponen SA (Strongly Agree) dan A (Agree) lebih tinggi jika dibandingkan komponen D (Disagree) dan SD (Strongly Disagree). Berdasarkan grafik tersebut dapat disimpulkan bahwa responden telah setuju sistem mudah digunakan untuk implementasi di Odoo12 ERP.

Pada Gambar 15, grafik menunjukkan komponen A lebih tinggi dibandingkan SD. Meskipun komponen SA lebih rendah dari $\mathrm{D}$, dapat disimpulkan bahwa sebagian besar responden setuju bahwa sistem memiliki tingkat usability yang baik. Namun, masih perlu diperbaiki lagi karena sebagian responden juga menyatakan bahwa usability pada sistem komisi belum baik dan masih perlu ditingkatkan.

\section{UAT - Usability}

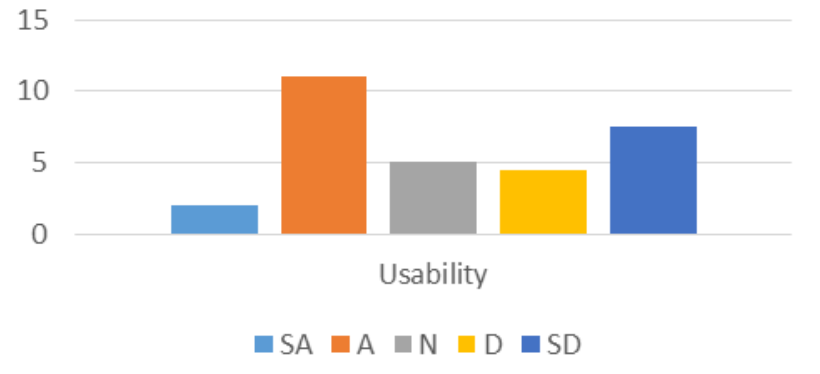

Gambar 15. Grafik UAT - Materi Uji Usability

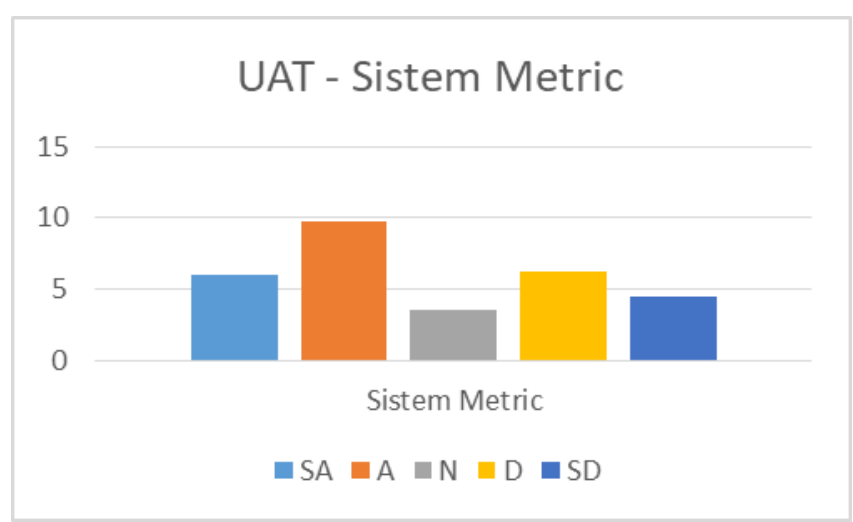

Gambar 16. Grafik UAT - Materi Sistem Metric

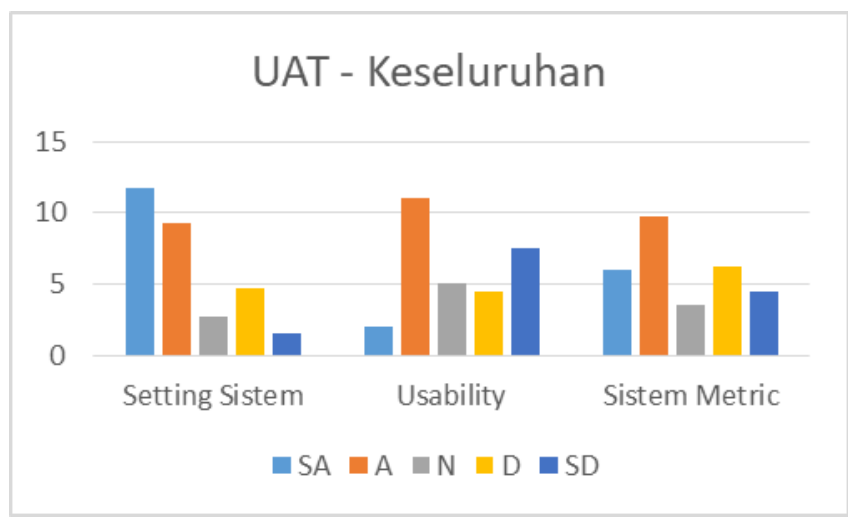

Gambar 17. Grafik UAT - Keseluruhan Metrik Uji

Pada Gambar 16, grafik menunjukkan komponen SA dan A lebih tinggi dari komponen D maupun SD. Hal ini menunjukkan bahwa sebagian besar responden setuju bahwa sistem komisi berdasarkan sistem metric menghasilkan hasil uji yang baik. Responden setuju sistem komisi sesuai dalam metric responsive, fungsionalitas, performa dan real-time.

Jika keseluruhan hasil uji ditampilkan dalam bentuk grafik seperi pada Gambar 17, kami menyimpulkan bahwa prototype sistem komisi layak digunakan dalam implementasi pada Odoo 12 ERP. Berdarkan masing masing materi uji, sistem mampu memberikan solusi terhadap permasalahan yang dianalisis yaitu mengenai ketidaksesuaian pemberian komisi terhadap sales. Selain itu, sistem komisi juga mampu memberikan solusi terhadap permasalahan eksekusi waktu. Pada uji sistem metric, responden setuju diatas $50 \%$ sistem mampu memberikan informasi cepat dan tepat. Meskipun, ada beberapa bagian dari sistem komisi harus diperbaiki dan ditingkatkan untuk peningkatan usability pada sistem.

\section{Kesimpulan}

Odoo12 yang telah digunakan oleh perusahaan sebelumnya mampu menunjang transaksi penjualan dalam 
jangka waktu harian, mingguan atau bulanan. Namun, pada kasus pemberian sistem komisi, Odoo12 belum terdapat fungsi tersebut. Perlu adanya sistem baru untuk menunjang pemberian komisi kepada sales. Hanya saja, jika sistem dirancang secara terpisah perlu adanya integrasi dengan Odoo12.

Pada penelitian ini, sistem komisi yang dikembangkan secara prototype langsung diimplementasikan pada Odoo12. Jadi, secara otomatis sistem komisi langsung terintegrasi dan sinkronisasi dengan data perusahaan pada Odoo12. Sistem komisi tersebut digunakan sebagai penunjang bagi manajer dan salesperson dalam menentukan besaran komisi yang diberikan. Sistem komisi yang dikembangkan terdiri dari fitur commission rule, commission list, wizard, dan credit note. Masing - masing fitur tersebut ditujukan untuk menunjang pembuatan commission rule oleh manajer. Jika pada sistem sebelumnya tidak ada konfirmasi nota invoice. Maka pada sistem komisi yang diusulkan, pembuatan commission rule telah diatur hak aksesnya dan sistem secara otomatis menentukan besaran komisi berdasarkan invoice yang telah dikonfirmasi.

Berdasarkan hasil uji white box, sistem secara internal telah sesuai dengan dokumen perencanaan. Hasil uji menunjukkan adanya kesesuaian dengan scenario uji. Pada uji UAT, hasil uji menunjukkan bahwa secara keseluruhan dari materi uji responden menyatakan sistem komisi layak untuk digunakan pada Odoo12 bagi manajer dan salesperson. Meskipun, ada beberapa bagian yang harus diperbaiki untuk meningkatkan usabilitas dari sistem komisi. Pada penelitian selanjutnya, perbaikan sistem komisi berdasarkan materi usabilitas sistem dan penambahan modul - modul yang mendukung proses bisnis penjualan.

\section{Ucapan Terimakasih}

Terima kasih kepada Portcities Indonesia (PCI) yang telah memberikan dukungan dan saran terhadap penelitian ini.

\section{Daftar Pustaka}

[1] A. S. Prabowo and N. W. Rahadi, "Sistem Informasi Industri Kecil Menengah Berbasis Sentra Menggunakan Metode Rapid Application Development," Infotekmesin, vol. 11, no. 1, pp. 37-43, 2020.

[2] N. Chasanah, P. Diantono, M. N. Faiz, J. Soetomo, N. Karangcengis, and K. Cilacap, "Implementasi Metode
Waterfall dalam Sistem Informasi Knowledge Management untuk Digital Marketing," J. Infotekmesin, vol. 12, no. 01, pp. 71-80, 2021.

[3] A. S. Prabowo and L. Syafirullah, "Rancang Bangun Sistem Informasi Usaha Mikro Kecil Menengah Studi Kasus Dinas Koperasi UMKM Daerah Istimewa Yogyakarta," $J$. Infotekmesin, vol. 9, no. 2, pp. 2-6, 2018.

[4] N. Limantara and F. Jingga, "Open source ERP: ODOO implementation at micro small medium enterprises: (A case study approach at CV. XYZ in module purchasing and production)," in 2017 International Conference on Information Management and Technology (ICIMTech), 2017, pp. 340-344.

[5] R. Stair and G. Reynolds, Fundamentals of Information Systems. 2012.

[6] P. S. Budi Darma and N. G. P. Wirawati, "Pengaruh Pendapatan Kamar dan Biaya Komisi Penjualan Terhadap Average Room Rate Hotel di Daerah Denpasar," E-Jurnal Akunt. Univ. Udayana, vol. 27, p. 2129, 2019.

[7] O. A. Ipuele and M. Benue, "Strategic Sales Force Compensation and Performance of Selected Breweries in Nigeria," Int. J. Adv. Res. Manag. Soc. Sci., vol. 8, no. 9, pp. 131-153, 2019.

[8] R. Amelia, "Sistem Informasi Perhitungan Komisi Agen Asuransi Pt . Asurani Kredit Indonesia Kantor Cabang," vol. 2, pp. 61-66, 2019.

[9] Syahputra, "Pengembangan Sistem Informasi Transaksi Penjualan Dan Komisi Agen Berbasis Web," Sist. Inf. trnasaksi, vol. 3, no. 4, pp. 3451-3460, 2019.

[10] N. L. Margareta and A. Pataropura, "Design And Development Of Sales E-Monitoring Information System Case Study: PT. Pratama Inti Distribusindo," bit-Tech, vol. 1, no. 1, pp. 40-45, 2018.

[11] J. Y. Wu and L. T. Chen, "Odoo ERP with Business Intelligence Tool for a Small-Medium Enterprise: A Scenario Case Study," ACM Int. Conf. Proceeding Ser., pp. 323-327, 2020.

[12] N. Irianis, W. Puspitasari, and M. Saputra, "How to Create E-Purchasing Based on Open ERP for Integrated Hospital Service System Using Quickstart Methodology," Int. J. Innov. Enterp. Syst., vol. 4, no. 02, pp. 72-81, 2020.

[13] M. Adhi Prasnowo et al., "Designing odoo's enterprise resource planning (ERP) in micro, small and medium enterprises (MSMEs)," J. Phys. Conf. Ser., vol. 1175, no. 1, 2019.

[14] C. Y. Gómez-Llanez, N. R. Diaz-Leal, and C. R. AngaritaSanguino, "A comparative analysis of the ERP tools, Odoo and Openbravo, for business management," Aibi Rev. Investig. Adm. e Ing., vol. 8, no. 3, pp. 145-153, 2020.

[15] A. Dennis, B. H. Wixom, and R. M. Roth, System Analysis and Design 5th Edition. 2012. 